\title{
Musik Patrol dan Identitas Sosial GAMAN di Surabaya
}

\author{
Julista Ratna Sari ${ }^{1}$ \\ Universitas Negeri Surabaya
}

\begin{abstract}
Patrol Music and Social Identity of GAMAN in Surabaya. In the globalization era, local traditions do not always experience cultural weaknesses. Patrol music tradition of GAMAN (Anti Narcotics Youth Movement) Surabaya is one of the performing arts that has grown from local traditions. This study aims to describe the way GAMAN creates a social identity with an artistic nuance. The researcher used the phenomenology approach. Data was obtained based on participants observation, in-depth interviews, and documentation. The results of this study shows that there is a sustainable process of invented of tradition which is fully supported by the globalization process existing in the realm of a showcase which is derived from the development of patrol music tradition of local sahur.
\end{abstract}

Keywords: patrol music; GAMAN; kentongan

\begin{abstract}
ABSTRAK
Di era global, tradisi lokal tidak selalu mengalami pelemahan budaya. Tradisi musik patrol GAMAN (Gerakan Anak Muda Anti Narkoba) Surabaya adalah salah satu seni yang tumbuh dari tradisi lokal. Penelitian ini bertujuan untuk mendiskripsikan cara GAMAN menciptakan identitas sosial bernuansa seni. Peneliti menggunakan pendekatan fenomenologi. Data diperoleh berdasarkan observasi partisipasi, wawancara mendalam, dan dokumentasi. Hasil penelitian ini menunjukan adanya proses invented of tradition secara berkesinambungan yang didukung penuh oleh proses globalisasi yang ada pada ranah sebuah pertunjukan dari pengembangan tradisi musik patrol sahur lokal.
\end{abstract}

Kata kunci: musik patrol; GAMAN; kentongan

\section{Pendahuluan}

Patrol merupakan musik tradisional rakyat yang tergolong jenis musik hiburan. Waktu pementasan dilakukan setiap malam selama bulan Ramadhan. Patrol digunakan oleh masyarakat Jawa Timur untuk meronda dalam memeriahkan dan menyemarakkan suasana malam bulan Ramadhan. Adapun pelaksanaannya dimulai tengah malam dan selesai menjelang pukul $03.00 \mathrm{WIB}$ saat orang yang menjalankan ibadah puasa akan bersantap sahur.

Musik patrol masih banyak diminati masyarakat tradisional karena keunikan simbolisasi permainan dan lantunan musik-nya. Keindahan lantunan musik patrol me-nawarkan nilai artistik melebihi musik-musik pop-modern. Musik patrol dapat membuat para pendengarnya seakan-akan menyatu dengan alam. Oleh karena itu, patrol masih dilestarikan atau dijaga eksistensinya oleh masyarakat modern saat ini.

Patrol mempunyai nilai-nilai filosofis kealaman dalam setiap ritme bunyinya. Secara tersirat, musik tradisional ini berusaha untuk menyadarkan manusia bahwa manusia dan alam merupakan kesatuan yang bersifat saling membutuhkan. Untuk itu, hubungan antara manusia dengan alam harus seimbang. Artinya, manusia tidak boleh merusak alam jika tidak ingin dirusak oleh alam.

Sebagian besar masyarakat menamai musik patrol ini sebagai musik kentongan. Kentongan biasanya digunakan pada patroli atau ronda malam. Selain itu, bunyi kentongan juga digunakan sebagai

\footnotetext{
Alamat korespondensi: Program Studi Pascasarjana Pendidikan Seni Budaya, Universitas Negeri Surabaya.
} Jln. Ketintang, Surabaya. E-mail: julista2907@gmail.com; HP. +62 81357385745. 
alat komunikasi sederhana dalam kegiatan seharihari, seperti sebagai penanda bahaya maupun pengumuman dan penanda waktu. Fungsi utama bunyi kentongan adalah sebagai alat komunikasi berupa tanda peringatan dini bahaya, seperti banjir, kebakaran, atau pencurian. Bunyi kentongan memiliki ritme tersendiri berupa pukulan yang diatur sesuai kesepakatan di masyarakat, seperti satu pukulan yang dilakukan berulang kali menandai adanya tindak pencurian, dua kali pukulan terus menerus menandai adanya peristiwa kebakaran, dan lain-lain.

Persebaran musik patrol di Indonesia telah ada sejak masa pra Islam. Perkembangan dan modifikasi kentongan di beberapa tempat, seperti di Jawa dan sekitarnya, memiliki variasi yang berbeda. Sebagai contoh, di Madura, musik patrol disebut dengan musik tong-tong yang telah dikombinasikan dengan gamelan Jawa yang dirombak dalam pola permainannya. Ibnu (2004) mendeskripsikan pola dan kebiasaan yang dilakukan kelompok tongtong. Pola dan kebiasaan tersebut menyangkut model kreativitas yang dibentuk pada masingmasing kelompok. Setiap kelompok memiliki inovasi yang berbeda. Inovasi ini selalu ditunjukkan melalui adu kreativitas, baik dalam festival maupun pertemuan lainnya. Faizun (2013) menyebut music kentongan sebagai kesenian tek-tek. Tektek merupakan kesenian yang mirip dengan patrol hanya saja sebagian besar instrumen musik terbuat dari bambu, baik dalam bentuk kentongan maupun angklung. Kesenian tersebut mengkombinasikan alat modern, seperti drum, dan menghindari penggunaan instrument gamelan.

Rangkaian penelitian yang telah dilakukan sebelumnya, baik di Madura maupun di Cilacap, menunjukkan adanya modifikasi dan transformasi fungsi dalam perkembangan musik patrol. Hal yang sama terjadi di wilayah Surabaya. Modifikasi dan transformasi fungsi musik patrol yang dilakukan sejak tahun 2010 dipelopori oleh aksi grup GAMAN (Gerakan Anak Muda Anti Narkoba). Aksi GAMAN bertujuan untuk mengurangi tingkat kenakalan remaja serta menciptakan generasi muda sehat, beriman, dan berkualitas melalui berkesenian yang ditunjukkan lewat musik patrol. Kegiatankegiatan yang dilakukan meliputi penyelamatan, karawitan, teater, musik patrol, musik akustik, musik keroncong, band, futsal, volly, bulu tangkis, tenis meja, dan catur. Di antara berbagai kegiatan tersebut, musik patrol menjadi unggulan. Hal ini ditandai dengan pertunjukan musik patrol setiap menjelang acara ramadhan maupun acara kegiatan sosial (Ridiyanto, 2016).

Secara tidak langsung, berbagai kegiatan telah memberikan nilai-nilai positif yang melibatkan peran masyarakat dan anak-anak muda Surabaya yang turut berpartisipasi pada aksi GAMAN. Masyarakat diajak berperan aktif dalam rutinitas GAMAN. Masyarakat mendapatkan edukasi berupa norma-norma, nilai-nilai, dan moralitas dalam bersosialisasi. Sosialisasi merupakan pengalaman seumur hidup berupa norma dan nilai yang ditanamkan kepada anak-anak dengan penguatan yang lembut dan serangkaian pengalaman bersosialisasi yang lebih spesifik (Ritzer, 2012: 416).

Pembentukan identitas GAMAN Surabaya dalam memodifikasi musik patrol dan mentransformasi fungsi dari alat komunikasi penanda bahaya menjadi pertunjukan musik telah membuat generasi muda bersemangat untuk melestarikan musik tradisi. Fakta bahwa generasi muda bersemangat untuk melestarikan musik tradisi patrol tersebut adalah komposisi musik patrol yang dikemas dengan rancak meskipun alat musik yang dibawakan tidak bernada. Oleh karena itu, peneliti tertarik untuk meneliti pembentukan musik patrol sebagai aksi GAMAN yang menciptakan identitas kelompok tersebut. Fokus tulisan ini mengarah pada persoalan mengenai terbentuknya identitas sosial dan seni terkait dengan keberadaan tradisi musik patrol GAMAN Surabaya.

\section{Musik Patrol GAMAN Surabaya}

GAMAN atau Gerakan Anak Muda Anti Narkoba yang didirikan di Manukan Lor II F, Surabaya Barat, pada tanggal 1 Agustus 2010. Terbentuknya GAMAN dipelopori Ridiyanto (48 th), salah satu warga Manukan Lor.

Pada mulanya GAMAN terbentuk karena rasa prihatin terhadap korban-korban narkoba, terutama generasi muda di lingkungan Manukan. Tujuan dibentuk GAMAN adalah untuk mengurangi 
tingkat kenakalan remaja, tingkat korban narkoba, dan menciptakan generasi muda yang sehat, beriman, dan berkualitas dalam berkesenian.

"Melihat anak muda saat ini yang lebih aktif dan bersemangat, apalagi saat saur-saur bersedia berkeliling kampung sembari membunyikan kentongan untuk membangunkan warga muslim yang akan melaksanakan puasa, mereka tidak pernah merasa terpaksa dan lebih semangat mengikuti kegiatan saur-saur tersebut" (Ridiyanto, 2016).

Dengan dibentuknya GAMAN di daerah Manukan, kentongan yang semula digunakan saat sahur pada bulan Ramadhan beralih fungsi menjadi musik pertunjukan yang dikenal dengan musik patrol. Musik patrol yang awalnya dikemas untuk kepentingan mendukung pelaksanaan ibadah puasa dan menyerukan bahaya dini, beralih fungsi menjadi pertunjukan dalam sebuah aksi sosial tanpa menghilangkan tujuan awal terciptanya musik patrol.

Di zaman modern ini, musik tradisional patrol masih mampu menunjukkan eksistensinya di tengah maraknya budaya pop-modern, salah satunya dengan memberikan perubahan yang dominan, antara lain pada alat musik dan komposisi musiknya. Alat musik patrol GAMAN cenderung menggunakan alat musik pukul yang menghasilkan bunyi tanpa memperhatikan nada. Oleh karena itu, agar ketiadaan nada tidak menimbulkan kebosanan, anggota GAMAN berinisiatif untuk membuat alat musik dari bambu yang memiliki ukuran berbeda dengan nada yang diinginkan. Alat musik ini dinamakan quarto 1 dan quarto 2 (Gambar 1).

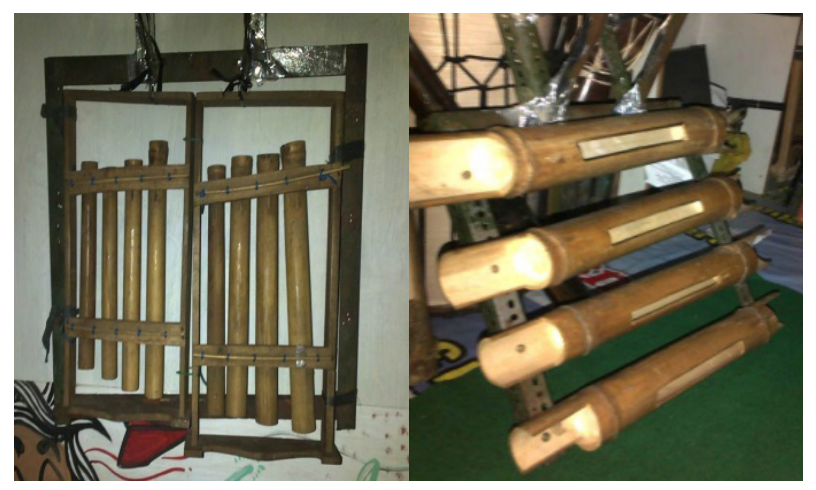

Gambar 1. Alat Musik Patrol GAMAN: Quarto 1 dan Quarto 2. (Foto: Julista Ratna Sari, 2016)
Komposisi musik yang dibuat juga memiliki ciri khas yang berbeda dengan musik patrol daerah lain. Terdapat pola ritmis yang rancak dan bersahutsahutan dengan alat musik lain (Gambar 2).

Permainan music patrol mampu membuat anak-anak anggota GAMAN lupa akan obat-obat terlarang seperti narkoba. Namun, kegiatan positif tersebut menimbulkan beberapa pandangan negatif dari masyarakat di sekitar Manukan. Pada awalnya sebagian besar masyarakat merasa terganggu akan gaduhnya suara-suara yang ditimbulkan oleh anakanak yang sedang latihan musik patrol. Terjadi konflik antara anggota GAMAN dan masyarakat sekitar. Akan tetapi oleh karena adanya sosialisasi dan rasa saling menghargai, konflik bisa diatasi.

GAMAN membuktikan bahwa kegiatan yang dilakukannya merupakan kegiatan yang positif. Ini ditunjukkan oleh pencapaian prestasi atau penghargaan, salah satunya melalui musik patrol (Tabel 1). Hasil penghargaan yang diperoleh GAMAN tidak berakhir pada ajang festival saja melainkan telah menjadi ikon musik patrol Surabaya. Hal ini dibuktikan dengan ditunjukknya GAMAN mewakili kontingen Indonesia dalam ajang pertunjukan musik internasional di Jepang tahun 2016.

Perubahan wujud patrol dari ritual membangunkan kaum muslim yang akan melaksanakan sahur pada saat bulan puasa hingga menjadi ajang pertunjukan inilah yang menjadi bukti bahwa musik patrol merupakan identitas GAMAN dalam berkesenian. Hal ini merupakan bentuk invented tradition yang menunjukkan tradisi patrol sahur lokal dapat memiliki daya saing yang cukup kuat di era global.

\section{Transformasi Musik Patrol}

Musik patrol merupakan bentuk transformasi dari alat komunikasi penanda bahaya menjadi musik pertunjukan dan penyemangat anak

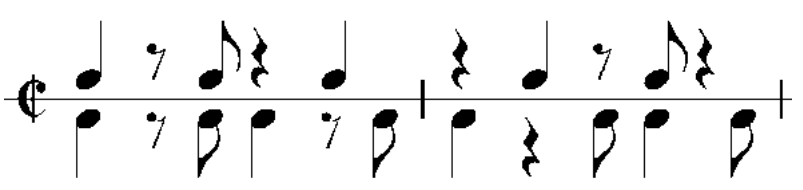

Gambar 2. Penggalan Rangkaian Pola Ritmis Musik Patrol GAMAN. (Foto: Julista Ratna Sari, 2016) 
muda. Kehadiran musik patrol ini juga didukung dengan modifikasi alat musik kentongan. Alat musik kentongan yang sederhana dibuat menjadi kentongan quarto. Perbedaan kentongan quarto dengan kentongan pada umumnya terletak pada ukurannya. Selain memodifikasi alat musik, patrol juga menambahkan beberapa alat musik yang berasal dari bambu (Ridiyanto, 2016).

Komposisi musik patrol yang terdengar didominasi sebuah bunyi ritmis dan nada tiup yang bersumber dari alat musik itu sendiri. Oleh karena itu, musik patrol tidak memerlukan suara vokal. Dengan demikian, munculnya bentuk baru dalam musik patrol GAMAN sesuai pernyataan Warsana (2012: 76-77) bahwa lahirnya sebuah karya musik merupakan perwujudan atau manifestasi diri yang dilatarbelakangi oleh pengalaman pribadi maupun lingkungan yang mempengaruhinya. Perkembangan bentuk seni pertunjukan yang dikemas GAMAN mengarah pada modifikasi dengan penambahan inovasi pada identitas patrol. Hal ini memberikan pengaruh pada ikon sosial dan seni kota Surabaya.

Identitas dimiliki individu maupun kolektif sehingga identitas didasarkan pada kesamaan atas pengalaman, penubuhan, dan konteks tertentu (Raditya, 2014:95). Pentingnya identitas dalam sebuah kelompok yaitu sebagai tanda pengenal kelompok tersebut. Suatu kelompok dianggap berbeda dengan kelompok lain apabila ia memiliki identitas. Identitas kelompok berfungsi sebagai pengacu keberadaan kelompok dalam lingkup yang lebih luas (Sabreen dan Allen, 1968; Castells, 2010). Hal tersebut juga terjadi pada kelompok GAMAN yang membentuk sebuah identitas baru dengan memodifikasi dan mentransformasi fungsi pada musik patrol.

Musik dalam keberadaannya memiliki nilai guna. Merriam (1964: 210) secara eksplisit menyatakan bahwa penggunaan musik lebih mengacu kepada cara masyarakat menggunakan musik tersebut. Merriam menitikberatkan pada praktik kebiasaan atau latihan musik yang menjadi habit atau kebiasaan.

When we speak of the uses of music, we are referring to the ways in which music is employed in human society, to the habitual practice or customary exercise of music either as a thing in itself or in conjunction with other activities. music is used in certain situations and becomes a part of them, but it may or may not also have a deeper junction. Use then, refers to the situation in which music is employed in human action.

Penelitian ini menemukan bahwa fenomena musik patrol di masing-masing daerah sendiri sebenarnya juga bukan sesuatu yang benar-benar tradisional, karena hal itu adalah tradisi. Berdasarkan pandangan Hobsbawn (2000) musik patrol ini adalah 'invented of tradition' yang artinya sebuah

Tabel 1. Prestasi Musik Patrol GAMAN.

\begin{tabular}{clll}
\hline No & \multicolumn{1}{c}{ Lomba/Festival } & \multicolumn{1}{c}{ Penyelenggara } & Prestasi \\
\hline 1. Musik Patrol Ramadhan 2010 & Flexi & Juara 1 \\
2. Musik Patrol 2011 & Kompas TV & Juara 3 \\
3. Musik Jalanan 2011 & Dinas Pariwisata Surabaya & Juara 2 \\
4. Musik Jalanan 2011 & Partai Gerindra & Juara 1 \\
5. Musik Patrol Pasar Malem 2012 & Pemda Surabaya & Juara 1 \\
6. Musik Patrol NU Expo 2012 & NU Jawa Timur & Juara 1 \\
7. Musik Patrol & Pemda Jawa Timur & Juara 1 \\
8. Musik Yel-Yel & Yamaha & Juara 1 \\
9. Musik Patrol Kota Surabaya 2013 & Dinas Pariwisata Surabaya & Juara 1 \\
10. Musik Perkusi/Patrol & Masjid Al-Akbar Surabaya & Juara 1 \\
11. Rapak Bedug & Kota Gresik & Juara 1 \\
\hline
\end{tabular}


kesatuan tindakan atas dasar aturan dan ritual atau simbol keaslian. Kegiatan tersebut memiliki fungsi dan nilai dari sebuah kebiasaan yang secara otomatis dipengaruhi oleh keberlangsungan di masa lampau, sehingga dapat disimpulkan bahwa karakter keseluruhan tereferensi dari masa lalu. Hal ini kemudian mereferensi GAMAN dalam beberapa aksi pemberantasan narkoba dengan berkesenian dan bersosialisasi.

Aksi GAMAN ini menguatkan identitas sosial. Identitas sosial adalah pandangan individu tentang dirinya selama orang tersebut berada dalam kelompok sosial tertentu. Identitas social menjadi bagian dari konsep diri yang berasal dari keanggotaan dalam satu atau beberapa kelompok sosial, dan dari evaluasi yang diasosiasikan dengannya (Rengganis, 2016).

Berdasarkan teori social identity, Tajfel dan Tunner (1982) mengemukakan bahwa prasangka terjadi biasanya disebabkan oleh in group favoritism, yaitu kecenderungan mendiskriminasikan dalam perlakuan yang lebih baik atau menguntungkan in group di atas outgroup. Teori tersebut dapat dikatakan bahwa seorang individu akan berusaha memilih dan memperteguh keyakinan untuk bergabung dengan kelompok favoritnya dibandingkan dengan kelompok lain. Lebih lanjut, Tajfel dan Tunner menyatakan bahwa orang berjuang untuk mendapatkan atau mempertahankan identitas sosial yang positif. Ketika identitas sosial dipandang tidak memuaskan, mereka akan bergabung dengan kelompok, tempat mereka sedang tergabung sebagai tempat yang lebih menyenangkan.

Pembentukan proses identitas dapat dibagi menjadi tiga tahapan, yaitu katagorisasi, identifikasi, perbandingan sosial (Tajfel dan Turner, 1982). Kategorisasi merupakan tahapan individu mengenali dan mengelompokkan adanya identitasidentitas berdasarkan kategori social, seperti etnis, ras, religi, pekerjaan, dan status sosial. Kategorikategori ini selanjutnya akan memberikan suatu pengertian tentang individu pemilik identitas.

Pada tahap identifikasi, individu mengidentifikasikan dirinya terhadap kelompok-kelompok tertentu, tempatnya terafiliasi. Identifikasi mengandung dua makna dari diri individu, yaitu: pertama, bahwa sebagian individu dapat dibangun berdasarkan keanggotaan suatu kelompok yang artinya terdapat pemikiran kamu vs mereka . Kedua, bahwa pada saat tertentu, individu berfikir bahwa dirinya sebagai diri, dan memandang orang lain sebagai liyan. Jadi, pada saat tertentu, individu memandang dirinya sebagai anggota suatu kelompok yang disebut social identity, dan pada saat yang lain memandang dirinya sebagai individu yang unik. Hal ini terkait dengan hubungan antara status dan peran sosial yang erat. Susanto (1979) menjelaskan bahwa status merupakan kedudukan obyektif individu dalam masyarakat yang memungkinkan individu untuk memiliki hak dan kewajiban yang melekat pada dirinya. Status ini akan tampak jika individu yang memiliki status menjalankan perannya dalam masyarakat.

Pada tahap perbandingan social, individu melakukan perbandingan antara dirinya dengan orang lain dalam rangka mengevaluasi dirinya. Pembentukan identitas terdiri dari unsur-unsur tertentu yang saling terkait, seperti halnya yang dinyatakan Burke bahwa identas seseorang atau kelompok merupakan wilayah, tempat bermacammacam agensi berperan (Burke, 2009:7). Pernyataan Burke menekankan bahwa dalam pembentukannya, terdapat agensi-agensi yang berperan. Terdapat faktor-faktor yang menjadikan sesuatu menjadi identitas. Agensi-agensi berperan sebagai pembentuk identitas. Identitas dimiliki individu maupun kolektif, sehingga dalam penerimaannya, identitas didasarkan pada kesamaan atas pengalaman, penubuhan, dan konteks tertentu.

\section{Pembentukan Identitas Sosial GAMAN melalui Musik Patrol}

Sebagian besar anggota GAMAN merupakan anak muda. Segala kegiatan yang ada di Sanggar GAMAN memiliki fungsi tersendiri bagi anak muda daerah Manukan, Surabaya. Kegiatan GAMAN yang paling unggul adalah kegiatan berkesenian, salah satunya melalui musik patrol. Di awal perkembangan musik patrol GAMAN yang berfungsi sebagai media dakwah yaitu pengingat waktu sahur pada saat bulan Ramadhan memberikan dampak positif bagi masyarakat 
karena bunyi musik patrol yang sangat keras dapat membangkitkan semangat untuk bangun tidur dan menunaikan sahur. Dengan demikian, secara tidak langsung, musik patrol berfungsi sebagai pendukung norma agama dan norma sosial.

Tidak cukup dengan kegiatan yang berkaitan dengan keagaaman, pendiri GAMAN, Ridiyanto, mencoba menarik perhatian masyarakat terutama generasi muda dengan berlatih musik patrol di halaman depan balai Manukan Lor. Musik patrol yang terdengar keras ketika dibunyikan menimbulkan ketertarikan anak-anak muda untuk mendatangi sumber suara dan mencari informasi terkait musik patrol. Hal ini seperti disampaikan Rizky berikut:

Para anak-anak muda daerah Manukan kalau mengenai musik-musik yang semangat seperti patrol ini, mereka pasti langsung bertanya "untuk ikutan gabung dalam latihan dan berkegiatan di GAMAN bagaimana Kak?” (Rizky, 2016).

Hal ini, secara tidak langsung, telah berfungsi sebagaimana acuan pada visi dan misi sanggar GAMAN untuk mengurangi tingkat kenakalan remaja dengan memotivasi generasi muda agar melakukan kegiatan yang positif melalui berkesenian, hubungan antara seni dan masyarakat yang juga menjadi kesatuan keindahan (Suryajaya. 2016). Hubungan estetika dalam peran kesenian musik patrol Sanggar GAMAN dapat dipahami dari seni dan masyarakat yang menjadi kesatuan keindahan, yaitu adanya satu fungsi peran atau nilai moral dalam sebuah seni.

Peran kesenian musik patrol GAMAN telah memberikan beberapa fungsi sosial dengan menunjukkan seni representasi objek. Seni representasi objek terbagi menjadi dua sisi yaitu sisi subjektif yang merujuk pada kemampuan budi untuk menilai makna atau menafsirkan objek seni dan sisi objektif yang mengacu adanya ukuran atau acuan, tetapi bukan dari ukuran kualitas melainkan tujuan karya seni (finalitas) yang bersesuaian dengan rasa senang yang dihasilkan (Ali, 2011). Di balik kegiatan dan pandangan positif dari masyarakat sekitar Manukan, ternyata terdapat beberapa masyarakat yang memandang kegiatan tersebut masih dalam tataran penilaian yang negatif, karena ketidakmampuan pemahaman dari masyarakat tersebut. Namun, ketidakmampuan pemahaman dapat diatasi dengan cara melakukan sosialisasi agar menjadi kesatuan utuh memahami kualitas objektivitas yang indah.

\section{Penutup}

Perubahan wujud musik patrol dari fungsi awal sebagai musik yang dimainkan pada saat menjelang waktu sahur pada bulan Ramadhan menjadi pertunjukan telah membuktikan bahwa musik patrol adalah identitas GAMAN dalam berkesenian sebagai salah satu invented tradition. Tradisi patrol sahur lokal memiliki daya saing yang cukup kuat di era global. Terdapat perubahan yang mendominasi bentuk music, yaitu antara alat musik dan komposisi musiknya. Alat musik patrol GAMAN cenderung menggunakan alat musik pukul yang lebih mengutamakan bunyi dibandingkan nada. Untuk mengurangi bunyi monoton dan kebosanan akibat tidak bernadanya alat musik yang dipergunakan, anggota GAMAN berinisiatif untuk membuat alat musik dari bambu dengan ukuran yang berbeda dengan nada yang diinginkan. Alat musik ini dinamakan quarto 1 dan quarto 2. Komposisi music yang dibuat menawarkan perbedaan dengan musik patrol daerah lain berupa pola ritmis yang rancak dan bersahut-sahutan dengan alat musik lainnya.

\section{Ucapan Terima Kasih}

Terimakasih kepada Ridianto dan para anggota GAMAN yang memberikan ijin melakukan observasi dan wawancara sehingga penelitian dapat terlaksana.

\section{Kepustakaan}

Ali, M. (2011). Estetika: Pengantar Filsafat Seni. Jakarta: Sanggar Luxor.

Barker, C. (2004). Cultural studies, theory \& practice. Yogyakarta: Kreasi Wacana.

Castells, M. (2010). Power of Identity Second Edition. United Kingdom: Wiley-Blackwell.

Faizun. (2013). Kesenian Tradisional Tek-Tek 
Lokal Jaya Di Desa Jenang Kecamatan Majenang Kabupaten Cilacap: Kajian Bentuk Pertunjukan Dan Fungsi. [Skripsi]. Program Studi Pendidikan Seni Drama, Tari, Dan Musik. Fakultas Bahasa Dan Seni. Universitas Semarang.

Featherstone, M. (1999). Global Culture: Nasiolism, Globalization and Modernity. California: Sage Publications Ltd.

Hobwbawn, E., \& Terence, R. (2000). The Invention of Tradition. Melbroune: Cambridge University.

Ibnu (2004). Seni Musik Tong-Tong di Kabupaten Sumenep. [Skripsi]. Program Studi Antropologi. Fakultas Ilmu Budaya Universitas Brawijaya Malang.

Merriam, A. P. (1964). The Anthropology of Music. Northwestern: University Press.

Raditya, M. H. B. (2014). Musik sebagai Wujud Eksistensi dalam Gelaran World Cup. Resital Jurnal Seni Pertunjukan, 15(1), 83-99.

Rengganis, D. A. (2016). Kontribusi Identitas Sosial terhadap Konformitas pada Penggemar K-Pop. Jurnal Ilmiah Psikologi, 9(2), 161-167
Ritzer, G. (2012). Teori Sosiologi: Dari Sosiologi Klasik Sampai Perkembangan Terakbir Postmodern. Yogyakarta: Pustaka Pelajar.

Suryajaya, M. (2016). Sejarah Estetika: Era Klasik Sampai Kontemporer. Jakarta: Indie Book Corner.

Susanto, P. A. S. (1979). Pengantar Sosiologi dan Perubahan Sosial. Bandung: Binacipta.

Tajfel, H. (1982). Social Identity and Intergroup Relation. England: Cambridge University Press.

Tunner, J.C. (1982). Toward Cognitive Redifination of the Social Group. England: Cambridge University Press.

Warsana. (2012). Tumpang Tindih: Sebuah Komposisi Musik dalam Interpretasi Personal. Resital Jurnal Seni Pertunjukan, 13(1), 74-94.

\section{Informan}

Ridiyanto (48 th). Pemimpin dan Pendiri GAMAN. Tinggal di Surabaya.

Rizky (30 th). Anggota GAMAN. Tinggal di Surabaya. 


\section{INDEKS SUBJECT}

A

angklung $43,44,45,46,47,48,49,50,51,52$, 169

apropriasi budaya 27

\section{B}

balungan gending $11,103,106,108,109,111$, 126

\section{D}

DaminatilaFont $53,54,55,56,58,59,60,61$, 62

disrupsi musik 144, 149, 157

dramatik naratif 13,22

E

Eeewahh 78, 80, 81, 82, 83, 84, 85, 86

G

GAMAN 168, 169, 170, 171, 172, 173, 174

gamolan 159, 160, 161, 162, 163, 164, 165, 166,167

ghendhing dangdut $113,114,116,118,120$, $122,124,125,126,127,128,129,130$, 132

\section{I}

Indragiri 95, 96, 97, 102

J

jula-juli $1,2,3,4,5,6,7,8,9,10,11$

$\mathbf{K}$

karawitan Surakarta 103

kentongan $161,168,169,170,171$

L

Ladrang Sobrang $103,104,105,106,107,108$, $109,110,111,112$

Lakon IBU 13, 14, 16, 18, 24

M

$\operatorname{minimax} 65,68,75,77$ mogers 21

musik bambu 43, 44

musik bandar $27,28,29,30,32,34,36,38$, 40,42

musik batu $65,66,67,69,70,71,72,73,74$, 75,76

musik eksperimen 65

musik Lampung 159, 161

musik Madura 113, 116, 129

musik metal islami 133

musik Pandalungan 1

musik patrol 168, 169, 170, 171, 172, 173, 174

musik Sunda 43, 53

musik Surabayan 1

\section{$\mathbf{N}$}

Nandung 95, 96, 97, 98, 99, 100, 101, 102

notasi kendang $53,54,55,56,57,58,59,60$, 61,62

$\mathbf{P}$

Palembang 38, 88, 89, 90, 91, 92, 93, 94

Pancaran Senja $78,79,80,81,82,85,87$

pernikahan melayu 88

purgatory $133,134,135,136,137,138,139$, $140,141,142$

\section{$\mathbf{R}$}

rentak joget $33,78,79,80,81,82,83,84,86$, 90

\section{S}

sastra lisan Riau 95

seni liberal 144

seni pesisir 27

\section{$\mathbf{T}$}

tabbhuwân $113,114,115,116,117,118,119$, $120,121,122,123,124,126,127,128$, 129, 130, 132

Teater Koma 13, 14, 15, 17, 18, 24, 25, 26

teatrikal musikal 13 


\section{INDEKS PENGARANG}

\begin{tabular}{|c|c|c|c|c|c|}
\hline \multicolumn{2}{|c|}{ Budi, Dinda Satya Upaja } & \multicolumn{4}{|c|}{ Nalan, Arthur S. 13} \\
\hline \multicolumn{2}{|c|}{ Ch. R., Wisma Nugraha } & Rahmat, Sujud Puj & i Nur & 133 & \\
\hline \multicolumn{2}{|c|}{ Djohan $\quad 65,159$} & $\begin{array}{l}\text { Saepudin, Asep } \\
\text { Sari, Julista Ratna }\end{array}$ & $\begin{array}{l}53 \\
168\end{array}$ & & \\
\hline \multicolumn{2}{|c|}{ Harsawibawa, A. $\quad 133,144$} & Setiawan, Aris & 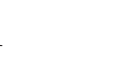 & & \\
\hline \multicolumn{2}{|c|}{ Hidayatullah, Panakajaya 133} & $\begin{array}{l}\text { Setiawan, Sigit } \\
\text { Simatupang, G.R. }\end{array}$ & $\begin{array}{l}113 \\
\text { Lono L }\end{array}$ & toro & 133 \\
\hline \multicolumn{2}{|c|}{ Ihsan, Rivaldi 78} & $\begin{array}{l}\text { Slamet, R. Chairul } \\
\text { Sriwulan, Wilma }\end{array}$ & $\begin{array}{c}65 \\
78\end{array}$ & & \\
\hline \multirow{2}{*}{\multicolumn{2}{|c|}{$\begin{array}{lc}\text { Kautzar, Awang } & 88 \\
\text { Kurniawan, Adi } & 159\end{array}$}} & Suardi, Rofiandri & 95 & & \\
\hline & & $\begin{array}{ll}\text { Sunarto } & 95 \\
\text { Suyanto } & 1\end{array}$ & & & \\
\hline \multicolumn{6}{|l|}{ Martarosa 27} \\
\hline
\end{tabular}

\section{Ucapan Terima Kasih}

Ucapan terima kasih disampaikan kepada para Mitra Bebestari:

Prof. Dr. I Nyoman Sedana (Institut Seni Indonesia Denpasar)

Prof. Dr. Djohan (Institut Seni Indonesia Yogyakarta)

Prof. Dr. Endang Caturwati (Institut Seni dan Budaya Bandung)

Prof. Dr. Ted Tsung Tsai (Graduate School of Ethnomusicology, Tainan National University of the Arts, Taiwan)

Dr. Made Mantle Hood (University Putra Malaysia)

Dr. Ratna Noviani (Kajian Media dan Budaya, Universitas Gadjah Mada Yogyakarta)

Dr. Wisma Nugraha Chr (Universitas Gadjah Mada Yogyakarta)

yang telah membantu menyeleksi artikel dan memberi saran perbaikan kepada para penulis Jurnal Resital Volume 18 No.1 Juni 2017, Volume 18 No.2 Agustus 2017, dan Volume 18 No.3 Desember 2017. 


\section{WRITING INSTRUCTIONS}

\section{Title}

[Title must succinctly describes the contents of the research article and attract the academic readers. The title consists of 8-12 words, not including definite article (the) and indefinite article ( $a$, an). Use the phrases, not sentence.].

\section{Author(s)}

[Author must fill out author's profile that consist of author First, Middle and Last Name (If author only uses one name, fill the first name and last name with the same name), Gender, Initial, Username, Password, Affliation (University/Institution), E-mail, Mailing Address (complete address of affiliation), Country and Bio Statement. Author(s) must follow the journal template which can be downloaded at http://journal.isi.ac.id/index.

php/resital

\section{ABSTRACT}

The abstract is a summary of the article. It is consist of aim/goal/problem of research, research methods, results and discussion, and conclusion. Implications or recommendation can be added in the abstract. The abstract must be written in 150-250 words. The abstract must not contain lengthy background information and have no reference to figure, table, equation, any bibliographical reference either coming within or other article. The language of abstract must be clear and concise. It is a stand-alone summary in one paragraph.

Keywords: it contains 3-5 important words that are taken from the title and the content of the paper

\section{Introduction}

The introduction show what is already known from the previous studies, defines the importance of the study, literature review, and state the research question. In order to understand what is already known from the previous study, the introduction must consist of discussing the relevant journal article (with citation) and summarizing the current understanding of the problem encounter. The methods explain clearly how the author carried out the research. The method must describe the research design clearly, the replicable research procedures, describe how to summarize and analyze the data.

\section{Result and Discussion}

The result section shows objectively the presentation of the research key results without any interpretation using text, tables and figures. The result section begins with text, presenting the key finding, and referring to the tables and figures. The table must not print screen, specific numerical values, compare and contrast values, and minimum of 2 row and column. The figures must clear (provide original file as supplementary file in article submission), highlight trends, pattern, and relationship. The result section must present how the author ensure the data validity and reliability

The discussion section shows how the author interprets the results in light of what are already known, and to explain the new understanding of the problem after taking your results into consideration. The discussion must connect with the Introduction so it tells how your study contributes to the body of knowledge and society.

Tabel 1. Student Distribution Frequency

\begin{tabular}{|c|c|c|c|c|}
\hline No. & Interval & Frequency & $\%$ & Category \\
\hline 1. & $85-100$ & 59 & 28.36 & Very Good \\
\hline 2. & $75-84$ & 93 & 44.71 & Good \\
\hline 3. & $65-74$ & 37 & 17.78 & Average \\
\hline 4. & $55-65$ & 19 & 09.15 & Bad \\
\hline & Jumlah & 208 & 100.00 & \\
\hline
\end{tabular}

Figure 1. Speed Changing Tool
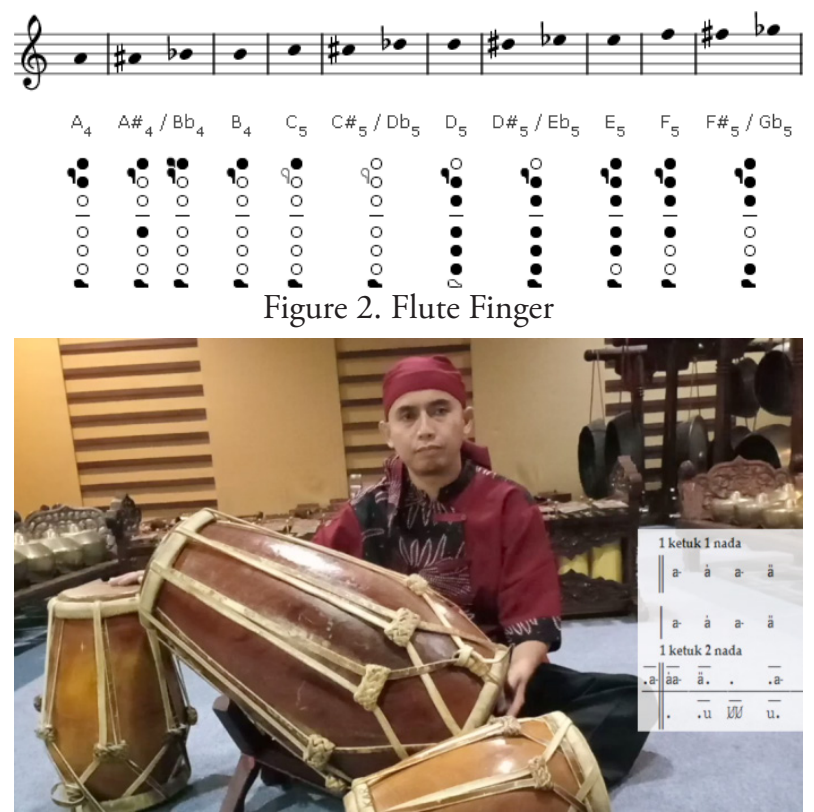

Figure 3. Kendang Practice (Source: Asep, 2017) 


\section{Conclusion}

The conclusions section show the answer or clarification of the research questions and opportunities for future research.

\section{References}

The reference must consist of $80 \%$ from relevant and recent primary sources (such as article of journal or conference from last 5 years). The reference must be written in APA style and using reference manager software Mendeley.

\section{Journal Article}

B Budi, D. S. U., Soedarsono, R. M., Haryono, T., \& Narawati, T. (2014). Angklung Dogdog Lojor pada Upacara Seren Taun. Resital: Jurnal Seni Pertunjukan, 15(2), 139-151. Retrieved from http://www.journal.isi.ac.id/index.php/ resital/article/view/848.

\section{Book}

Suharto, Edi. (2014). Membangun Masyarakat Memberdayakan Rakyat: Kajian Strategis Pembangunan Kesejahteraan Sosial \& Pekerjaan
Sosial. Bandung: Refika Aditama.

\section{Thesis, Dissertation, and Research Reports}

Prasetya, H.B. (2012). Melesed dan Nggandhul dalam Karawitan Pedalangan Gaya Yogyakarta. Universitas Gadjah Mada Yogyakarta.

\section{Conference Proceedings}

Muthmainnah, L. (2017). Perancangan Kampanye Penanggulangan Dampak Lagu Dewasa Terhadap Anak-Anak. e-Proceeding of Art and Design, 4(2), 138-146.

\section{Audio/Video}

Sugito, Hadi. (2005). Lakon Semar Gugat. (Cassete). Semarang: Fajar Record.

\section{Informant}

Handiman (79 years old). Angklung Craftman who is the student of Daeng Sietigna. Jln. Surapati No. 95 Bandung 40123.

\section{Article Submission}

Article should be uploaded through Open Journal System of http://journal.isi.ac.id/index.php/resital 